\title{
Ecología en prácticas cotidianas
}

\section{Artículo de reflexión}

\section{Elizabeth Garavito López}

Universidad Distrital Francisco José de Caldas

elizagaravito@gmail.com

Recibido: 5 de septiembre de 2017

Aprobado: 15 de febrero de 2018

Cómo citar este artículo: Garavito López, Elizabeth (2018). Ecología en prácticas cotidianas. Calle14: revista de investigación en el campo del arte 13 (24) pp. 410426. DOI: https://doi.org/10.14483/21450706.13535

Agradecimientos: A la Universidad Distrital Francisco José de Caldas, quien ha financiado el desarrollo de este proyecto de investigación, y a la Universidad Estadual Paulista Júlio de Mesquita Filho donde curso mis estudios de doctorado. Al grupo de personas que han participado en la creación de sus microuniversos: Adela López, Ana Lucrecia Clavijo Velásquez, Flor María Vargas Coneme, David Santiago Correa Estepa, Dora Carolina Ballén Robles, Jenny Marcela León León, Lady Dayana González Cita, María Clementina Cuéllar Camelo, Nancy Stella Reyes Rivera, Nohora Inés Castro Rivera, Norma Constanza Zamora, Olga Margoth Hernández, Olivia Rivera de Castro, Oswaldo Reyes, Stella de Reyes. 


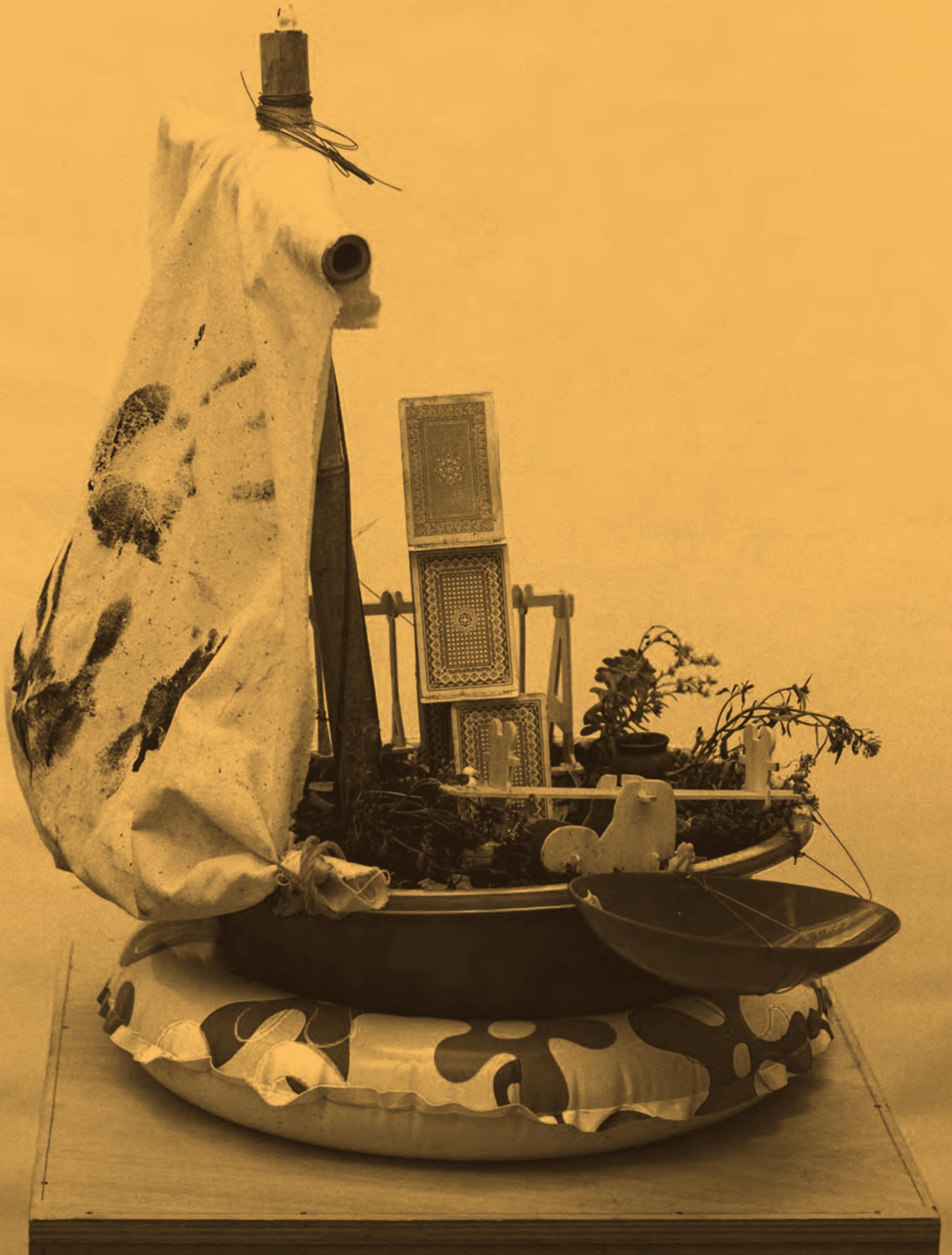




\title{
Resumen
}

El presente trabajo da cuenta de un proceso que parte de las prácticas cotidianas de los participantes en el que se acude a las narrativas no verbales generadas en estos espacios, en este caso, a través de la construcción de microuniversos (pequeños relatos que se construyen con plantas y objetos dentro de una maceta). Se ha desarrollado con un grupo de personas en la Facultad de Artes -ASAB, de la Universidad Distrital Francisco José de Caldas en la ciudad de Bogotá, a partir de una serie de talleres abiertos al público, que desde de la práctica misma indagaban la potencialidad de estos escenarios como "prácticas artísticas colaborativas".

\section{Palabras claves}

Artes colaborativas, ecología humana, vida cotidiana.

Ecology in everyday practices

\begin{abstract}
The present article gives an account of a process that starts from the daily practices of the participants and in which the non-verbal narratives generated in these spaces are employed. In this case, through the construction of microuniverses (small stories that are built with plants and objects inside a pot), the potential of these scenarios as "collaborative artistic practices" has been developed with a group of people from the Faculty of Arts ASAB of the Francisco José de Caldas District University in Bogota. This process has been carried out from an ecosystems perspective, entering into dialogue with concepts of relational art, community art and art with communities. Their starting point was the knowledge of the participants, from which a series of activities were planned, almost all focused on field work. Based on these experiences, the construction of microuniverses that were configured from their own narratives was later proposed.
\end{abstract}

\section{Keywords}

Collaborative arts, human ecology, daily life.

\section{L'écologie dans les pratiques quotidiennes}

\section{Résumé}

Cet article fait état d'un processus qui part des pratiques quotidiennes des participants et qui va aux récits non verbaux générés dans ces espaces. Dans ce cas, par la construction de microunivers (histoires courtes qui sont construits avec des plantes et des objets dans un pot), le potentiel de ces scénarios en tant que «pratiques artistiques collaboratives» a été développé avec un groupe de personnes de la Faculté des Arts ASAB de l'université Francisco José de Caldas à Bogota. Ce processus a été réalisé dans une perspective écosystémique, en entrant en dialogue avec les concepts d'art relationnel, d'art communautaire et d'art avec les communautés. Leur point de départ fut la connaissance des participants, à partir de laquelle une série d'activités ont été prévues, presque toutes axées sur le travail de terrain. Sur la base de ces expériences, la construction de microunivers configurés à partir de leurs propres récits a été proposée.

\section{Mots clés}

Arts collaboratifs, écologie humaine, vie quotidienne.

\section{Resumo}

O presente artigo investiga um processo que parte das práticas cotidianas dos participantes, trazendo narrativas não verbais geradas nestes espaços que, neste caso, se dá através da 
construção de microuniversos (pequenos relatos que se constroem com plantas e objetos dentro de um vaso de barro). 0 processo se desenvolveu com um grupo de pessoas na Faculdade de Artes -ASAB, da Universidade Distrital Francisco José da Caldas na cidade de Bogotá, a partir de uma série de oficinas abertas para o público, que desde as práticas mesmas, indagavam a cerca da potencialidade destes pequenos cenários como "práticas artísticas colaborativas". A investigação foi realizada a partir de uma perspectiva ecossistêmica, em diálogo com conceitos da arte relacional, a arte comunitária e a arte com comunidades. Seu ponto de partida foram os saberes próprios dos participantes, com os quais realizaram-se uma série de atividades, quase todas focadas nas atividades do campo. Com base nestas experiências se propôs a construção de microuniversos que foram produzidos a partir de suas próprias narrativas.

\section{Palavras chaves}

Artes colaborativas, ecologia humana, vida cotidiana.

\section{Maillallachiska:}

Nukanchimanda kami llapa vale sachukupi kaugsai, kaipi nukanchi kawanchimi llakukunata, sachakunata ima kaipi kausaskata chasa mana tukuringapa, allillami iachankuna tukuikuna imasam ka suma pueblumanda, karupi, kaugsai kam pudinguimi, wiñachinga, ima munaska, kunaura iachachunakumi, imasam llukanchi kawai kawaringa kunaurramanda kunata sakikungapa.

\section{Rimangapa Ministidukuna:}

Rurai aidachispa, Nukanchipa kaugsai, Tukui punchakuna kaugsai. 


\section{Preámbulo}

Ecología en prácticas cotidianas es un proyecto que se ha gestado en las sutiles relaciones y colaboraciones de un grupo de personas en la ciudad de Bogotá, Colombia. Este proceso se ha llevado a cabo en un jardín olvidado de la Facultad de Artes ASAB, de la Universidad Distrital Francisco José de Caldas, desde donde se convocó abiertamente a las personas a intervenir este espacio y desarrollar en él diferentes conquistas. A través de estas acciones, que denominé "ecolaborativas", he ido construyendo paralelamente un diálogo en el que se formulan preguntas y se indaga sobre los diferentes conceptos alrededor de las prácticas artísticas relacionales, colaborativas y dialógicas. Con esto pretendo comprender los procesos de creación en las prácticas cotidianas y sus potencialidades como prácticas artísticas colaborativas en un grupo de personas a través de la construcción de microuniversos. Estas narrativas, que vi por primera vez en la casa de mi madre, me revelaban que en cada rincón había historias que ella no me contaba con palabras; eran relatos de una gran riqueza, cargados de contenidos simbólicos; más que representaciones, eran pequeños puntos que se conectaban con sus universos de existencia. Más tarde, me percaté de que esta actividad se desarrollaba con mucha frecuencia en otros hogares, entonces me pregunté: ¿qué historias cuentan estos escenarios?, ¿de qué lugares hablan?, ¿qué conectan?, ¿qué tejen?, ¿qué recrean?

La idea de colaborar como práctica artística ha sido desarrollada por una cantidad significativa de artistas en los últimos dos siglos; sin embargo, propuse este proyecto para acercarme a la comprensión de algunas cuestiones relacionadas con este tipo de prácticas. En este punto, ciertos elementos aportados por el construccionismo social fueron una contribución importante para el proceso; tomé algunos de sus métodos como las prácticas narrativas y ciertos recursos dialógicos y colaborativos, que constituyeron en un material fundamental para el desarrollo del trabajo.

Es importante señalar que el punto de partida del constructivismo social es su cuestionamiento a los metarrelatos de la modernidad y su identificación con las posturas posmodernas; sin embargo, esta perspectiva, a partir de una postura decolonial y en un contexto específico, desde el cual quiero hablar, no podría ser muy útil dado que, como lo menciona Walter Mignolo (2010), los conceptos de modernidad y posmodernidad se originan en Europa y su historia interna; no son conceptos globales ni universales, fueron conceptos locales

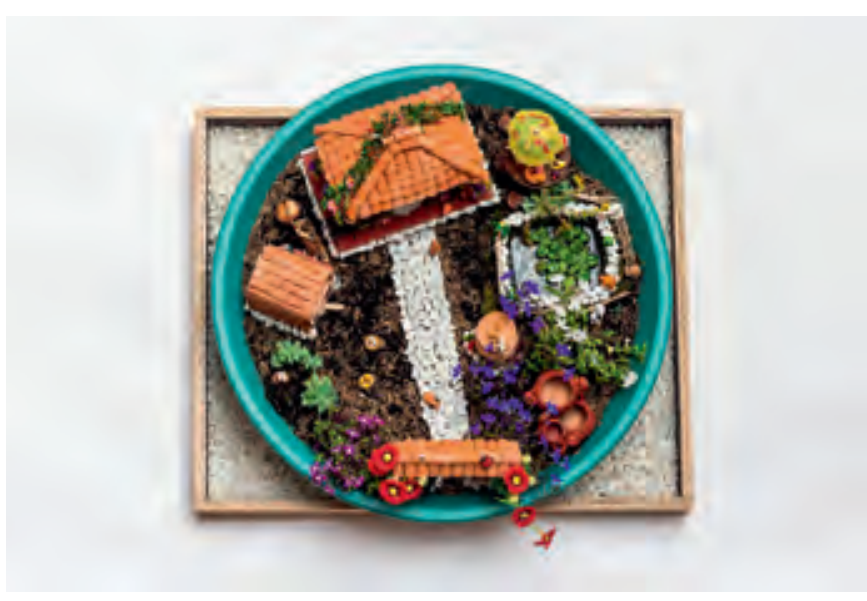

Imagen 1. El microuniverso de Nancy Stella Reyes. Fotografía: Andrea Ortíz Díaz (2014).

usados para el sometimiento de otros pueblos. Por otra parte, los conceptos de un yo y un otro también son derivados de esas epistemes, convirtiendo a las personas latinoamericanas en este caso, en extranjeros, migrantes, extraños: los eternos otros.

En este punto, es central preguntarnos qué tan aplicables son los discursos del construccionismo social, así como los emergidos de los centros de poder sobre las artes colaborativas, dialógicas, relacionales y contextuales, en un ámbito localizado en una ciudad de Colombia, un país de Suramérica que tradicionalmente no está inscrito como un participante activo en el circuito internacional de las artes. ¿Podrían estos discursos dar cuenta suficiente de lo que sucede en un territorio localizado y específico como el colombiano? Para abordar esta cuestión fue muy importante recurrir al pensamiento decolonial que se plantea como un pensamiento fronterizo y promueve lo comunal como otra alternativa al capitalismo y al comunismo, siendo este un proyecto que no pretende contribuir a la reoccidentalización ni a la desoccidentalización, sino que se propone como otra fuerza que, si bien surge de ambos proyectos, reclama su lugar en el proceso de construcción de futuros posibles, que no siendo ajenos a los paradigmas y las epistemes dominantes, los deja de lado como referencia de legitimidad para proponer opciones alternativas emergidas de otras realidades invisibilizadas históricamente (Mignolo, 2010).

Teniendo en cuenta que el arte y sus definiciones también están generalmente ligados e estas epistemes dominantes, reflejándose esto en una compleja red que involucra diferentes dimensiones, y circulando dentro de un sistema con un sinnúmero de desequilibrios, 


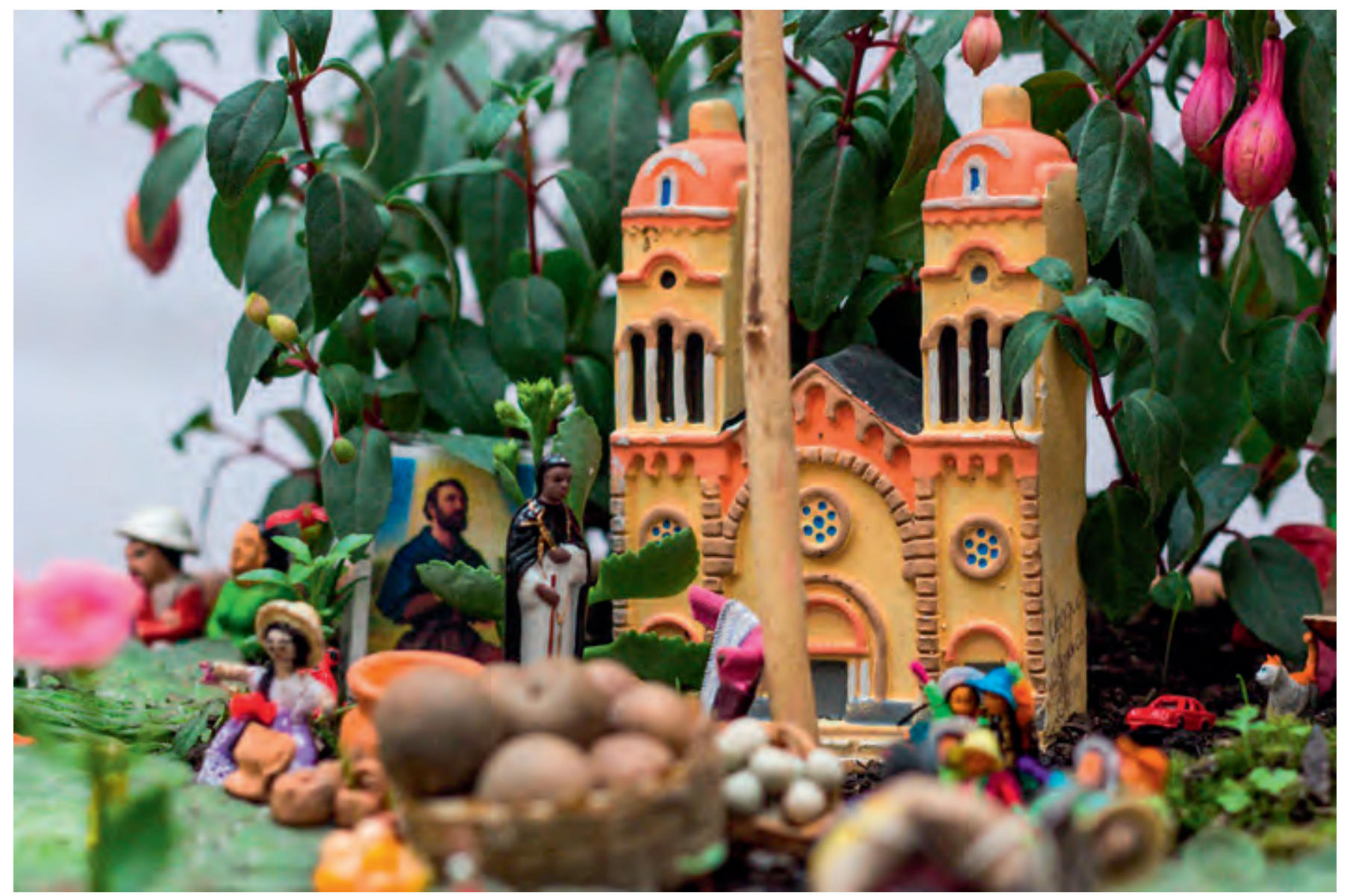

Imagen 2. El microuniverso de Clementina Cuéllar. Fotografía: Andrea Ortiz Díaz (2014).

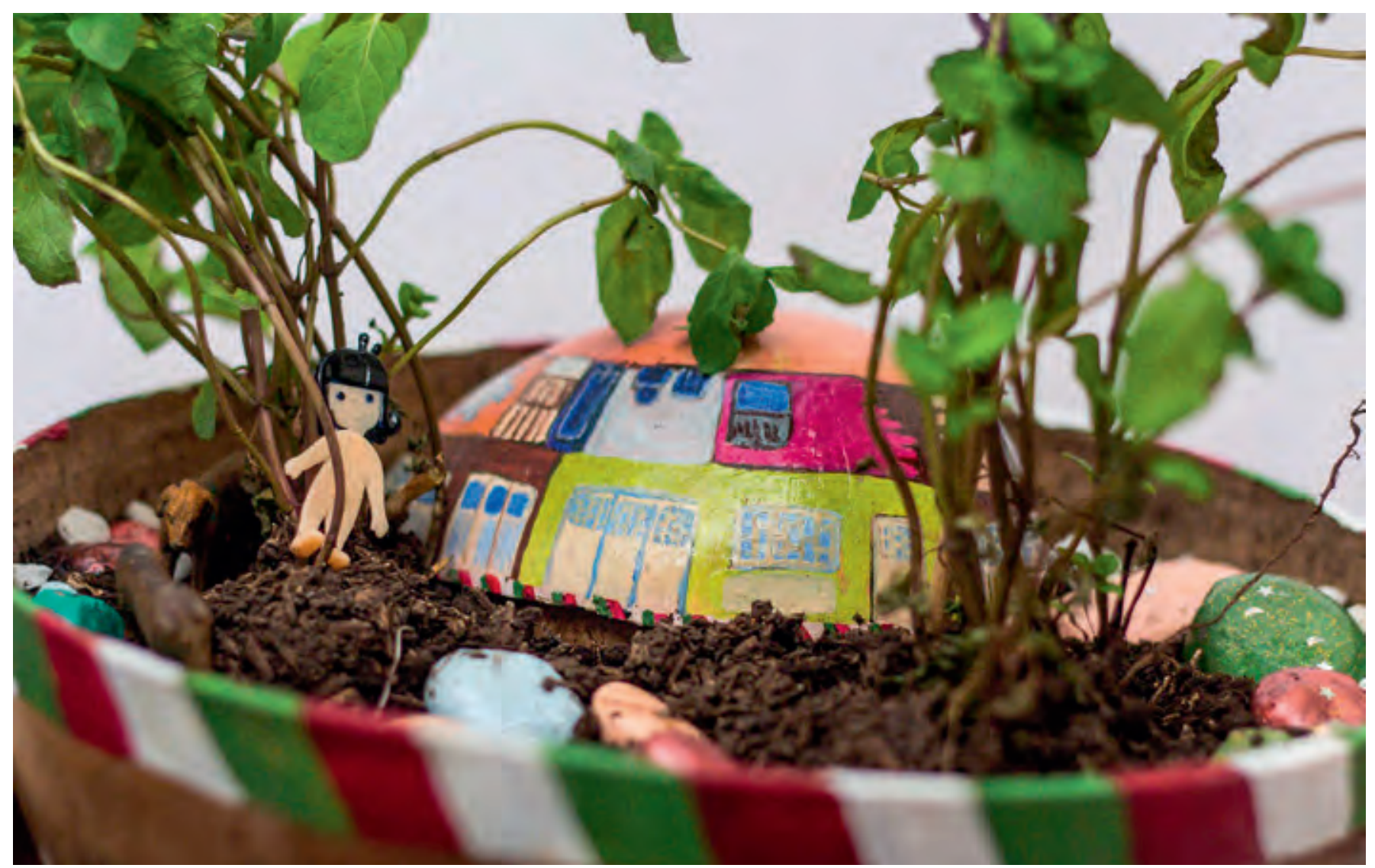

Imagen 3. El microuniverso de Marcela León. Fotografía: Andrea Ortiz Díaz (2014). 
fracturas y acuerdos que incluyen y excluyen tanto a las personas como a las prácticas, no me referiré en este proyecto al arte en general sino a unas prácticas particulares que, en algunos casos, circulan alrededor de este sistema, pero que frecuentemente se desplazan y se articulan en contextos diferentes.

Una de las dificultades que se le presenta a estas prácticas para ser incluidas en los discursos contemporáneos tiene que ver con que las herramientas de análisis que se utilizan comúnmente para el estudio de las artes son insuficientes para entender procesos tan dinámicos, disímiles y variables. Así, lo que termina identificando la existencia de estas prácticas como "prácticas artísticas" es su vinculación con el sistema de las artes que se basa en la exclusión y la jerarquización como ejercicios principales. Por estas razones, existe un infinito número de prácticas que quedan sin ser estudiadas, pero que indudablemente tienen una acción concreta en la poética del mundo y de la vida.

Como una manera de abordar el proceso, me acerqué al paradigma ecológico entendido, según Edgar Morin y Nicolás Hulot (2008), como “(...) un conocimiento organizativo global que es el único capaz de articular las competencias especializadas para comprender las realidades complejas" (p. 33). Desde esta óptica se podría asumir la creación en la cotidianidad como causa y efecto transformador dentro de sistemas complejos. Desarrollé esta investigación en sintonía con la perspectiva ecosistémica, articulando una serie de experiencias, ideas, acciones, procesos, pensamientos y teorías que resuenan entre sí.

La experiencia del proceso de "Ecología en prácticas cotidianas" fue co-construida con los participantes como coautores; las decisiones y las rutas que íbamos trazando nacían de las charlas de la cotidianidad en aquel jardín. A partir de esta experiencia identifiqué una serie de relaciones y la forma en que cada una hacía eco en las otras, e intenté construir con ellas un tejido que le diera consistencia a esta investigación y que interconectara la base que dio origen a este trabajo: la experiencia ecolaborativa de "Ecología en prácticas cotidianas" y las reflexiones que se derivan de esas conexiones.

\section{Ecología en la vida humana}

Ecología en prácticas cotidianas se ha desarrollado con un grupo que fue transformándose durante el proceso. Las realidades de las personas que acudieron eran diversas; en el recorrido nos adentrarnos en los espacios de nuestra cotidianidad para leernos en sus registros e intentar comprendernos como productores de un sistema en permanente cambio. Comenzamos con la idea de intervenir un jardín urbano, ubicado en el interior de la Facultad de artes ASAB de la Universidad Distrital Francisco José de Caldas; nos dimos cita en este espacio identificados, en primera instancia, con una sensibilidad ecológica común que, en principio, se podía entender como de cuidado del medio ambiente. Posteriormente realizamos una serie de actividades que nos llevaron a establecer otro tipo de relaciones; más allá de entender lo ecológico como un problema de las relaciones del ser humano con su medio ambiente, intentamos abordar nuestro proceso desde la perspectiva, planteada por Edgar Morin (1996), de un pensamiento ecologizado como un nuevo paradigma en el que los seres humanos se conciban a sí mismos como auto-eco-organizadores.

Morin se refiere al ecosistema como un conjunto eco-organizado de todos los seres del planeta, donde todos somos coautores, cooperadores y programadores de nuestro propio desarrollo y en el que existen múltiples tipos de relación: de asociación, de complementariedad, de jerarquías, de regulaciones, etc. (Morin y Hulot, 2008), lo que a su vez produce ciclos, procesos, inicios, finales... la vida, los días, los deseos, las pasiones, los sueños... todas las emociones y los sentimientos; esto que a veces creemos único y eterno va deslizándose en movimientos cíclicos que aparecen y desaparecen a veces sin apenas dejar rastro. Es en el ecosistema donde podemos entender nuestro proceso evolutivo y comprender claramente que los seres humanos somos solo una pequeña parte de la naturaleza en el conjunto de todos los seres vivientes (Novo, 2007); este concepto nos permite por algunos momentos dejar esa mirada de nosotros como centro y distanciarnos un poco de nuestro ego dictador para entendernos como una parte del sistema, que de la misma manera que nos necesita puede prescindir de nosotros, y recordar que durante miles de años de evolución millones de especies fueron conformando complejas comunidades, tan sincronizadas que si lo viéramos a la distancia podríamos pensar en un organismo multicriatural (Capra, 1998), del cual no solo no podemos escapar sino que formamos parte fundamental.

La inclusión de la perspectiva ecológica en la modernidad capitalista se presenta como una propuesta disidente; en consecuencia, un pensamiento que si bien parece incorporado como discurso en cada una de las 
agendas políticas, sociales y humanas, en su práctica aún dista mucho de estarlo en la vida como una opción que nos permita fluir en equilibrio en un mundo desigual y dividido. Ahora, si bien el pensamiento ecologizado se presenta como un nuevo paradigma en debate con las condiciones actuales de vida, es importante no olvidar que "el problema ecológico no solo nos concierne en nuestras relaciones con la naturaleza, sino también en nuestra relación con nosotros mismos" (p. 25). La existencia en armonía con un pensamiento ecológico replantea radicalmente nuestra forma de vernos, de crecer, de sentir, de transformarnos. Es como un yo único que ha construido una historia particular, con una memoria específica, que se relativiza y se diluye cuando se pone en relación; esta experiencia modifica drásticamente cada uno de nuestros relatos. Esto se hizo muy evidente durante el transcurso del proyecto Ecología en prácticas cotidianas, pues cuando nuestras narrativas tomaron forma en microuniversos generaron diálogos y, a su vez, estos reordenaron y recrearon permanentemente las miradas que teníamos sobre nuestra propia historia y las formas de pensar y accionar nuestras vidas.

La evolución hacia este nuevo paradigma va en la misma vía de la propuesta del artista alemán Joseph Beuys, quien planteó una práctica artística más allá de los objetos, que se enfoca en una poética humana en la que nos asumiríamos como seres creadores y capaces de autodeterminarnos. Esta nueva forma de estudiar y comprender nuestra existencia desde un paradigma ecológico ha permitido que otras disciplinas, entre ellas el arte, problematicen sus propias prácticas y métodos; así, el siglo XX, especialmente, se vio enriquecido por una serie de aportes de artistas que participaron en la transformación de diferentes contextos y dirigieron sus prácticas artísticas concretamente como dispositivos eficaces para el desarrollo social.

Las prácticas artísticas que apuntan tanto a la participación colectiva como a la generación de lazos y redes fueron definidas por varios teóricos, entre ellos Nicolás Bourriaud (2006), quien definió las estéticas relacionales como un "(...) conjunto de prácticas artísticas que toman como punto de partida teórico y práctico el conjunto de las relaciones humanas y su contexto social, más que un espacio autónomo y privativo" ( $p$. 142), o Paul Ardenne (2006), quien identificó las artes contextuales como las prácticas artísticas cuyo punto de partida no son las ideas propias del autor sino las de quienes pertenecen a un contexto específico, contribuyendo a él de manera participativa. En esta línea, Grant Kester (2004) definió las artes dialógicas como aquellas que se enfocan en propiciar espacios de diálogo entre los participantes, mientras que Suzy Gablik (1995) se concentró en las estéticas conectivas, las cuales vierten su interés en la generación de comunidades. Por su parte, Reinaldo Laddaga (2006) observa la contribución de algunas prácticas artísticas como acciones críticas ante un mundo capitalista y globalizado, a las que denomina "estéticas de la emergencia".

Si bien las artes históricamente han tenido un carácter relacional y conectivo, dado que complementan su sentido en la interacción social generando lazos que perviven históricamente y que nos conectan con siglos de existencia, son estas nuevas prácticas las que toman las mismas relaciones como material de su propuesta, planteándose como un intersticio social que permite relaciones entre las personas y el mundo (Bourriaud, 2006). Si ampliamos ese territorio de análisis, delimitado por estos autores específicamente a la esfera de la actividad artística respaldada por instituciones, encontramos que en el devenir de la vida cotidiana se producen, por artistas o no artistas, propuestas sobre nuevas formas de relacionarnos. Por lo tanto, en el proceso de Ecología en prácticas cotidianas nos ha interesado que queden inscritos los guiños, las risas, los lazos, el afecto; eso que nos une, eso que nos hace volver a buscarnos, a requerir la presencia de los otros; eso que nace por el contacto, por el solo hecho de compartir el espacio. Es fundamental reconocer que cada vez que generamos un espacio diferente para el encuentro, producimos también unas nuevas formas de relación que son precisamente las que nos enseñan maneras de habitar un mundo diverso y múltiple. Cuando salimos de los libretos conocidos, necesariamente creamos otras maneras de ser y estar; quizás sacamos de nuestro acervo oculto voces que teníamos calladas, silencios que esperaban ser palabra.

Al finalizar nuestro proceso, que se proponía como un escenario colaborativo dado a partir de una sensibilidad ecológica común, comprendimos que la idea de colaborar en sí misma no es suficiente cuando estamos pensando en cuidado, en redes, de cara a la cimentación de una vida distinta, una tierra cohabitada por todo tipo de seres que entienden, viven y respetan su diferencia en equilibrio y sincronía. En esta perspectiva, nuestras prácticas se definían mejor como ecolaborativas, en la medida en que las entendíamos como unas redes de colaboración, tanto entre seres autodeterminados como con la vida en todas sus formas. Desde esta óptica, podemos pensar en un arte que no esté enfocado meramente en grandes obras determinadas 


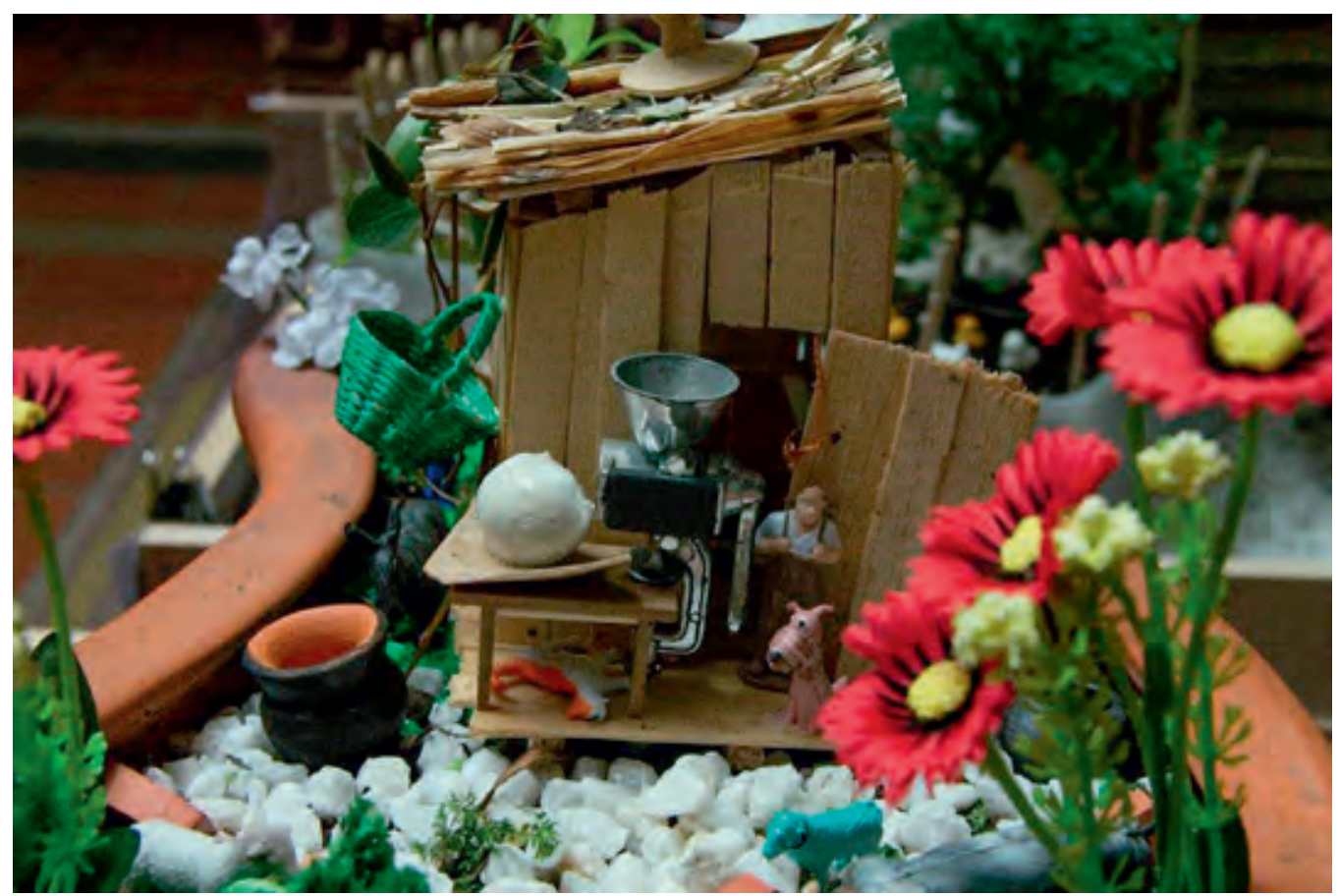

Imagen 4. El microuniverso de Margoth Hernández. Fotografía: Ligeya Daza Hernández (2014).

por el régimen de visibilidad artística, sino en la creación de otras nuevas formas sensibles y propuestas para una vida futura (Rancière, 2009); unas prácticas artísticas que hagan emerger los arcoíris poéticos que nos habitan; que conecten, colaboren y dialoguen con conciencia solidaria; que respondan con argumentos oportunos al sinnúmero de preguntas que gran parte de la producción artística del siglo XX y XXI ha dejado abiertas; un arte que, entendiendo la fractura, se atreva a lanzar puntadas poéticas en nuevas redes de sentido para una existencia en crisis.

\section{Poéticas de la cotidianidad}

Los talleres que desarrollamos tenían como finalidad explorar nuestra cotidianidad, desde el cuidado, con cuidado y para el cuidado, y las relaciones que se derivaron de este lugar a partir de las narrativas de los participantes. El territorio en el cual quisimos abordar nuestros relatos fue la cotidianidad de cada uno, teniendo en cuenta el aporte que hacemos en el marco de la vida cotidiana según nuestros propios horizontes de conocimiento, en la misma perspectiva desde la cual Rossana Reguillo (2000) señala la importancia de los elementos que constituyen y conforman la vida cotidiana como configuradores del mundo social e invita al estudio y al análisis de la misma como una rica fuente de información sobre lo que somos y nos forma.
El espacio de los talleres nos permitió separarnos un poco de nuestra cotidianidad y retomar sus poéticas. En aquel jardín no hacíamos nada diferente de lo que hacemos en nuestra vida diaria; sin embargo, en ese nuevo contexto nuestras repetidas acciones se reconfiguraban desde otras dimensiones. Los talleres, al mismo tiempo que hablaban de nuestra rutina nos sacaban de ella. Sobre esta experiencia, Carolina ${ }^{1}$ indica:

En medio del compartir el aprendizaje, logré encontrar un espacio de descanso distinto a la rutina diaria e incluso a los momentos de tensión que pueden consumirte en la ciudad.

Dentro del acervo de poéticas que cobran vida en nuestra cotidianidad nos detuvimos en una que condensaba muchas de las cosas que estábamos haciendo, como sembrar, regar, cuidar, crear, construir, contar historias..., así surgieron los microuniversos. Estas poéticas expresadas en pequeños jardines me son muy familiares porque con frecuencia viajo a la casa de mis padres, en Calarcá2 ${ }^{2}$ uno de tantos pueblos colombianos que descansa en la cordillera de los Andes. Es muy común encontrar en los rincones de mi casa silenciosas

\footnotetext{
1 Dora Carolina Ballén (2014), participante en Ecología en Prácticas Cotidianas.

2 Municipio del departamento del Quindío, ubicado en la cordillera central de los Andes colombianos.
} 


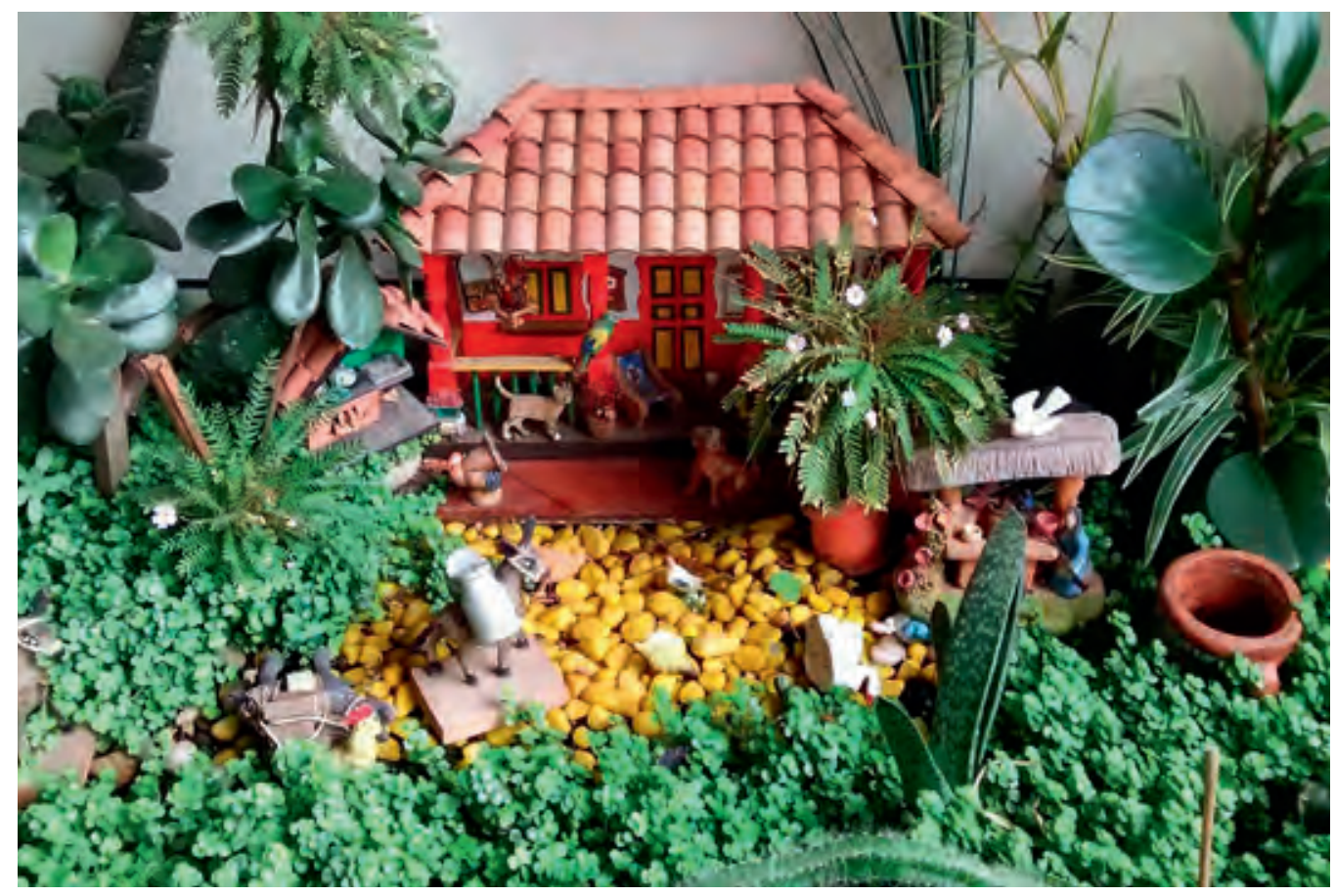

Imagen 5. El microuniverso de Adela López. Fotografía: Elizabeth Garavito López (2014).

historias delicadamente construidas con diversos objetos y plantas. Inicialmente pensaba que solo era la forma en que mi madre decoraba la casa; sin embargo, me inquietaban estas narraciones. Comencé a indagar un poco y me di cuenta de que mamá hablaba a través de ellas; no son construcciones caprichosas y sin sentido, al contrario, son relatos cada vez más complejos y ricos, allí está puesta su vida, que es la mía, esto que no decimos con palabras y se nos desborda de las manos.

\section{Cotidianidades}

La vida cotidiana es el territorio donde discurren los días de todos los seres del planeta. Podríamos decir que no existe un ser que no tenga cotidianidad; mientras tanto, esta misma generalidad hace que las variaciones de la vida cotidiana sean tan múltiples como las personas. Nuestra vida parece disolverse en lo cotidiano; son tan imperceptibles las transformaciones que allí ocurren, que lo cotidiano se nos revela como escenario mudo y sin alteraciones. A pesar de ser este el espacio donde reproducimos los modelos y las estructuras aprendidas, es también el territorio en el que se sedimentan, se nutren y ocurren las acciones que transformarán estas mismas estructuras.

Existen contribuciones significativas para el análisis de la vida cotidiana, tales como las de Henry Lefebvre
(1991), quien expresa que la vida cotidiana está relacionada con todas las actividades vitales, las conjuga y en ella se sintetizan también las diferencias y los conflictos; es el terreno que pone en común las diversas prácticas humanas, es el punto de encuentro y el vínculo entre ellas. Lefebvre considera que lo interesante en lo cotidiano no son concretamente las prácticas sino los encadenamientos y las redes que las integran, la manifestación en sentidos plurales y en espacios que moldean los seres humanos en el flujo permanente del tiempo. Sin embargo, la vida cotidiana sigue siendo el terreno de lo múltiple e indefinido; especialmente, parece ser el lugar de lo insignificante, lo vacío y lo homogéneo y, por eso, sin importancia. En palabras de Humberto Giannini (2004) "(...) cotidiano es justamente lo que ocurre cuando no ocurre nada" (p. 29); la cotidianidad es a veces el territorio del olvido hasta la muerte. Levantarse, tomar una ducha, preparar el desayuno, leer un poco, salir a la calle... La rutina es la forma en que discurre nuestra vida cotidiana y en la que incorporamos las normas y los valores sociales; es el marco de comportamiento donde intentamos ajustar nuestra existencia, es la manera de asegurarnos de que formamos parte de algo y estamos en sintonía con ello. La rutina es el dispositivo en que se configura lo cotidiano; ella está cargada de significados. A pesar de que la vida cotidiana reproduce el orden social y de que por la vía de la reiteración se normalizan una serie de prácticas, existe un margen de indeterminación relativa que transforma 


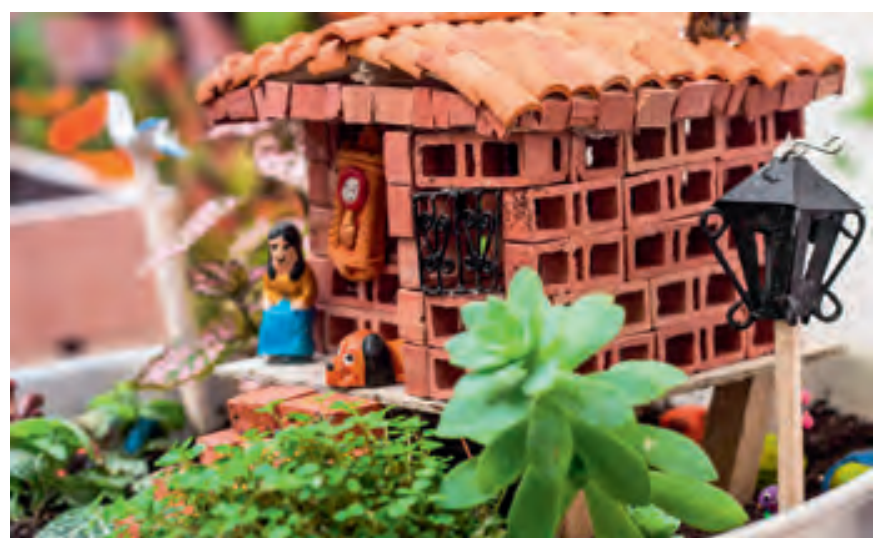

Imagen 6. El microuniverso de Dora Carolina Ballén. Fotografía: Andrea Ortiz Díaz (2014).

permanentemente nuestro universo simbólico. Lo cotidiano, con sus múltiples sentidos, es el territorio de donde se derivan identidades y papeles políticos importantes; es un lugar donde, según Michel de Certeau (1996), los practicantes inventan el presente hora tras hora, por eso en la acción de desdeñar lo adquirido desafían el futuro. Rossana Reguillo (2000) habla de la improvisación como uno de los ejes que dan forma a lo cotidiano, entendiéndola como el debate y el campo de acción en los que entran en juego las personas no solo con sus creencias, miedos y angustias, sino también con sus poderes, sus conocimientos y sus deseos.

\section{Creándonos en la cotidianidad}

Abordar la compleja articulación entre prácticas artísticas y potencialidad creadora humana, desde sus prácticas cotidianas y saberes, no niega el valor de los campos de diálogo que se pueden abrir con diversas esferas sociales, políticas y culturales; sin embargo, resulta vital que estos espacios de intermediación en relación con "lo social" contengan un carácter que vaya más allá de su procedimiento instrumental con las diferentes comunidades. En esta dirección es importante no perder de vista el enfoque de un proyecto como Ecología en prácticas cotidianas, en el que se propusieron los encuentros como espacios que, más allá de propiciar la creación de microuniversos, transformaran nuestra existencia. Las acciones y las experiencias generadas a partir del encuentro con el grupo fueron la raíz de un aprendizaje valioso, pues aportaron sentido de vida en el micromundo de la experiencia cotidiana. Santiago ${ }^{3}$ habla de lo que este espacio suscitó en él:

3 David Santiago Correa Estepa (2014), participante en Ecología en prácticas cotidianas.
(...) Una reflexión para darle valor a asuntos estéticos y no estéticos, en cuanto a las vivencias y experiencias de las personas que estuvieron a mi lado. Yo creo que es posible llevar eso a otros espacios y otros momentos de hombres y mujeres; es decir, a partir de esto, la relación con mi madre, o mi relación afectiva con alguien, ha cambiado.

Las narrativas de nuestros microuniversos juntaron palabras con objetos, contaron historias que crecían al tiempo que las plantas, recurrieron a la forma de las cosas y viajaron por la memoria al ritmo de nuestro tacto; trascendieron nuestras historias más allá de los discursos que cada uno había construido con su propio pasado y encontraron un camino para re-relatarlas. De esta manera, intentamos identificar los metarrelatos sobre los cuales están fundamentadas nuestras creencias y modos de asumir la vida, los relatos dominantes que nos determinan, acuerdos culturales y sociales que afectan nuestra versión de la propia vida, que son los que generalmente recordamos y de los cuales hablamos. Estos recuerdos son una selección de todo lo que ha sucedido en nuestra historia; surgen de acuerdos sociales y son tan solo una fracción de lo que vivimos, por eso "(...) aspectos de la experiencia vivida que quedan fuera del relato dominante constituyen una fuente, llena de riqueza y fertilidad, para la generación, o regeneración de relatos alternativos" (White y Epston, 1993, p. 32).

Generalmente, en nuestra forma de relatarnos hacemos una selección de lo que queremos hablar y “(...) dejamos de lado, de entre el conjunto de hechos de nuestra experiencia, aquellos que no encajan con los relatos dominantes que nosotros y los demás desarrollamos sobre nosotros mismos" (p. 29); por esta razón, gran parte de las cosas que nos suceden quedan sin ser dichas; sin embargo, cuando dejamos salir algunas historias comenzamos a recordar otras que estaban olvidadas porque eventualmente no las consideramos importantes. Nuestras historias de vida están hechas de innumerables textos, pero "llenos de vacíos"; por eso, narrar de diferentes maneras nos da la posibilidad de acercarnos a nuestra otra historia, porque "(...) estas lagunas ponen en marcha la experiencia vivida y la imaginación de las personas. Con cada nueva versión, las personas re-escriben sus vidas" (p. 30).

En el proceso de construcción de microuniversos, poco a poco trajimos a nuestras narrativas relatos subyacentes que también formaban parte de nuestra experiencia; aquí es importante tener en cuenta que otro aspecto esencial era re-narrar, a través de relatos no 
verbales, lo que nos permitía ampliar nuestro repertorio y entrar a nuestra propia historia por caminos menos racionales: otras versiones más emocionales de nosotros mismos. En ese sentido, Ana ${ }^{4}$ manifiesta que en el proceso aprendió que "...en realidad nunca es muy tarde para manifestar los sentimientos que tenía guardados", lo que evidencia que las personas vivimos más allá de la racionalidad y entremezclamos experiencia, recuerdos, deseos, sueños, miedos y una infinidad de sucesos como camino de aprendizaje y conocimiento.

\section{Crear en escenarios coloniales}

A pesar de que tenemos múltiples formas de narrar y de que son casi infinitas las posibilidades que existen para comunicar lo que somos y sabemos, es el saber letrado y académico el que normalmente es validado a partir del modelo colonial; así, "el saber intelectual o racional se convierte en la forma oficial de saber, y la institución educativa, al mismo tiempo, es instalada como forma de transmitir el conocimiento" (Garavito, 2013, p. 43); de esa manera, nuestro mundo actual está configurado alrededor de instituciones de saber especializado que regulan nuestra vida diaria y descartan otras infinitas posibilidades de conocimiento e intercambio social, determinando sus saberes como únicos y verdaderos, y desconociendo la infinita posibilidad de conocimientos alternativos de las personas. Es tan fuerte la imposición de estos saberes que permanentemente dudamos de los nuestros; por ello, un espacio como el propuesto por Ecología en prácticas cotidianas, donde se sugirió trabajar a partir de la construcción colectiva de saberes, no quedó exento de esta mirada y generó en los participantes la idea de asistir a un espacio para el aprendizaje de un saber institucionalizado. Al respecto de su experiencia, Ana dice:

(...) El primer día fue de miedos, de inseguridad, porque hacía muchos años no asistía a una clase; hacía tantos años que yo me había dedicado solo a mi trabajo (...), entonces el momento fue impactante, fue un momento muy importante, porque llegar allá, mucho más en una universidad, yo pensaba, ies imposiblei, ¿yo en una universidad en este momento? (...) para mí fue impactante aquel primer día.

\footnotetext{
$4 \quad$ Ana Lucrecia Clavijo (2014), participante en Ecología en Prácticas Cotidianas.
}

Aunque los aprendizajes, los saberes y las ejecuciones son tan diversos como las formas de estar y vivir en el mundo, no se puede ignorar que existe una valorización de algunos saberes sobre otros. Cuando se dio el proceso de colonización de América, los europeos, como pueblo colonizador, trajeron los patrones de significación y producción de conocimiento que estaban incorporados en su cultura, en su ideología y en su sistema educativo $y$, a partir de estos, borraron e inferiorizaron los conocimientos de los pueblos habitantes de América; Aníbal Quijano (2005) indica al respecto que "(...) los pueblos conquistados y dominados fueron puestos en situación natural de inferioridad, y consecuentemente también sus trazos fenotípicos, así como sus descubrimientos mentales y culturales" (p. 118). Es necesario destacar que el hecho de considerar el saber científico como supremo y no reconocer la producción de conocimiento de los pueblos invadidos fue el pretexto para implantar la ideología de que el saber del pueblo colonizador era superior; entonces, el conocimiento racional se convirtió en un elemento altamente poderoso a la hora de someter y justificar el derecho a esclavizar a los otros; estos colonizadores, “(...) entre la represión cultural y el genocidio masivo, llevaron a que las previas altas culturas de América fueran convertidas en subculturas campesinas iletradas, condenadas a la oralidad. Esto es, despojadas de patrones propios de expresión formalizada y objetivada, intelectual y plástica o visual" (Quijano, 1992, p. 13).

En este escenario, otras formas de conocimiento, como el corporal, el sensible, el práctico, etc., se tornaron marginales; es fácil percatarse de esto en el proyecto “Ecología en prácticas cotidianas", en el que se refleja un país complejo, múltiple, desigual, compuesto por personas tejidas con hilos de esta tierra y amarradas con nudos coloniales; sin embargo, también ha sido un espacio para re-crearnos, más allá de las marcas que han dejado estos nudos, reinventándonos, dibujando caminos no imaginados y pensando que es posible que este sea el "(...) tiempo de aprender a liberarnos del espejo eurocéntrico donde nuestra imagen es siempre necesariamente distorsionada. Es tiempo, de dejar de ser lo que no somos" (Quijano, 2005, p. 139).

\section{Conocimiento y cotidianidad}

Teniendo en cuenta que actualmente el mundo académico incorpora en su repertorio saberes "otros" como parte de su discurso, es importante reflexionar sobre el hecho de que las personas somos conscientes de que 


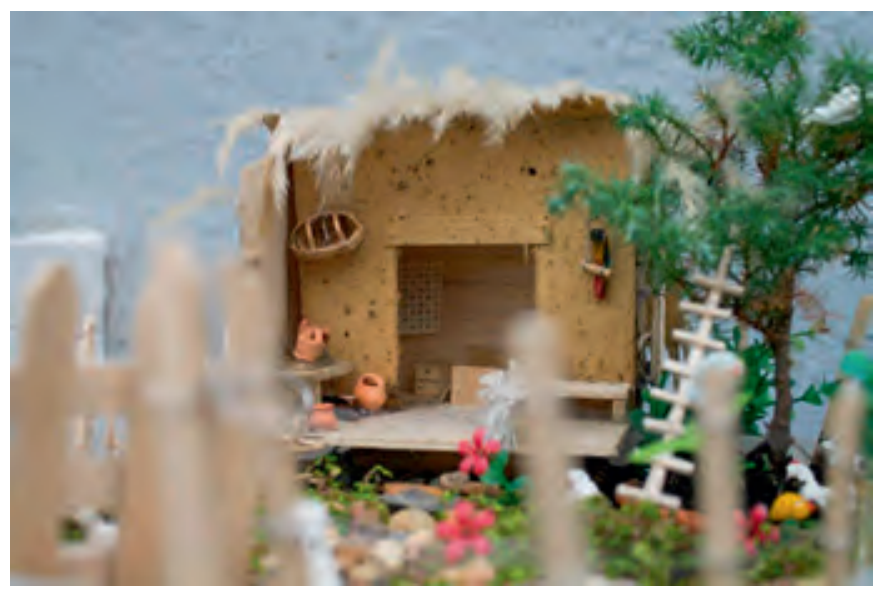

Imagen 7. El microuniverso de Ana Lucrecia Clavijo. Fotografía: Ligeya Daza Hernández (2014).

tenemos estos saberes y sobre el poder que subyace en ellos. Recorremos nuestra existencia haciendo uso de la riqueza de conocimientos adquiridos a lo largo de ella; a cada instante recurrimos a nuestro cúmulo de aprendizajes y los usamos sin dificultad porque no estamos siendo supervisados ni medidos, pues estos constituyen el saber necesario para actuar en el mundo; justo en ese territorio, nuestro saber toma otras formas y se recrea con nuevos significados mediante movimientos microscópicos. Al respecto, Rosana Reguillo (2000) afirma: "Sobre ciertas condiciones, la vida cotidiana puede ser pensada como un espacio clandestino en que las prácticas y los usos subvierten las reglas de los poderes" (p. 80).

Los conocimientos cotidianos deambulan en un territorio de incertidumbre, ya que la construcción cultural de sus características no tiene un soporte evidente ni claro, lo que les permite re-crearse permanentemente; esta aparente precariedad se refiere al hecho de que se tejen y articulan con los elementos que tienen a mano, con la vida misma, y no tienen necesariamente un norte para desarrollarse. Sobre este aspecto, Ana comenta:

Yo aprendí que las pocas cosas que tenemos en nuestro alrededor las podemos manifestar en cualquier momento y con cualquier persona, no necesariamente ocultarlas, o guardarlas, tenemos que exteriorizarlas; yo aprendí a exteriorizar y aprendí el valor de lo que yo tuve, de lo que yo viví algún día, de lo que fue algún día hoy hacerlo útil.

La importancia de esta investigación reside en que puede contribuir al reconocimiento, la legitimación y el empoderamiento de este tipo de saberes, no para homogenizarlos con el saber de la academia, pero sí para reconocerlos e ir borrando el paradigma sobre la jerarquía de los saberes. Sobre nuestro proceso, Nohora ${ }^{5}$ afirma:

\section{(...) Jamás pensé que alguna cosa que yo hiciese consiguiera recorrer lugares fuera de mi casa, que tuviese reconocimiento de todas las personas, que quisieran contemplar y admirar.}

Estas palabras evidencian la importancia que puede llegar a tener el desarrollo de proyectos como Ecología en prácticas cotidianas, no solo en la vida de las personas, sino en la formulación de preguntas que surgen del diario vivir y que deberían dialogar de una forma más armónica con el mundo académico.

\section{Creación-creatividad}

Históricamente el arte se ha alimentado de la cotidianidad, tanto de sus temas como de sus prácticas, instrumentalizándolas en innumerables ocasiones, para citar un ejemplo, en la Documenta 12, Kassel (Documenta und Museum Fridericianum Veranstaltungs- $\mathrm{GmbH}$, 2007), su director Roger Buergel abordó el tema de las disciplinas artísticas no museables e invitó a un reconocido chef, Ferrán Adrià, a participar como artista en este evento; de esta manera se concentró en la instrumentalidad de una práctica, que podría considerarse o no como artística, dejando de lado la pregunta sobre cómo un oficio cotidiano puede convertirse en arte, e intentando más bien exotizarla, dado su nivel de la "alta cocina", para que pudiera alcanzar ese status de "arte". Estas formas de jerarquización de las prácticas humanas dejan claro que el mundo académico otorga a las personas y a su vida cotidiana un estatus tangencial de creatividad subjetiva inferior al de creador; este carácter de inferioridad no proviene ni de su invisibilidad ni de su fraccionamiento, como tampoco de su temporalidad fugaz, sino de una carencia de discurso y espacio institucional que las soporte.

El artista alemán Joseph Beuys proponía borrar las líneas trazadas por la institución arte, convocando a la humanidad a retomar su propio poder de creación y transformación social; de ahí su afirmación "todo ser humano es un artista" (Bondenmann-Ritter, 2005), a través de la cual propuso un arte en las acciones, más allá

$5 \quad$ Nohora Inés Castro (2014), participante en Ecología en prácticas cotidianas. 


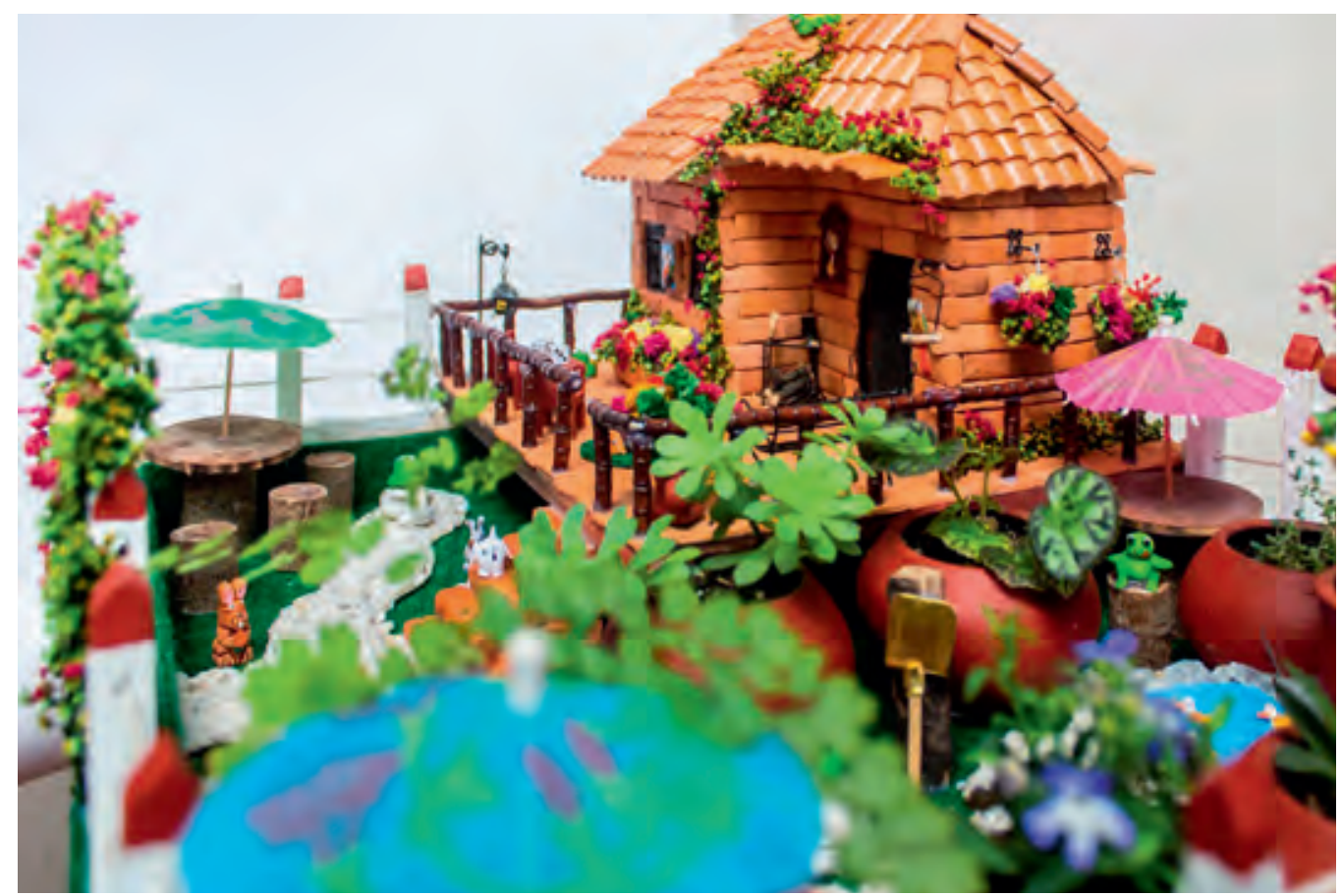

Imagen 8. El microuniverso de Nohora Inés Castro. Fotografía: Andrea Ortiz Díaz (2014).

de los objetos, que trascendiera los límites de su propio escenario y se centrara en el poder y los efectos de la acción. Sin embargo, crear sigue siendo una atribución casi exclusiva del campo del arte y para calificar las actividades surgidas de la cotidianidad se sigue usando la palabra creatividad, envolviéndolas así en discursos que reiteran una vez más la marginalidad de la cotidianidad humana; de ese modo, se aleja la atención de los ejercicios aparentemente menores e invisibles que ponen en cuestión el real potencial creador humano.

El concepto de creatividad se convierte en un slogan para referirse a las actividades que ayudan a aliviar el stress del trabajo o a compensar la vacuidad de la vida, como la del ama de casa. Esto reduce el concepto a las actividades estéticas triviales, propias de la esfera privada —un clásico ejemplo es la cerámica- (Joas, 1996, p. 72).

Creamos cuando transformamos en otros universos lo que existe. Cuando recorro la casa de mi madre, voy encontrando puertas con voces escondidas, creaciones entrelazadas con el tiempo en las esquinas, voces ocultas por los años, partes que aún no conozco de mi propia historia. Es una charla mágica, logro entrar en cada narración y escucho tantas voces como vacíos de mi historia familiar; es un encuentro dulce pero invisible, una puerta que algún día cruzaré, una puerta sin retorno. Son pequeños indicios de que la acción creadora sucede solo en espacios sensibles diferentes a nuestros espacios corrientes, son impulsos humanos para trascender el espacio ordinario, pero con elementos comunes; es por eso que, según Hans Joas (2002), “la creatividad se explica a partir de las posibilidades concretas exigidas por las situaciones también concretas. Las condiciones que las situaciones crean no son elementos limitantes, pero si son posibilidades" (p. 16).

Norma Constanza ${ }^{6}$ expresa que el proceso de construcción de microuniversos la llevó a recordar cosas que parecían olvidadas; estas fueron apareciendo, primero en sus sueños, luego en su conciencia. De esta manera, como los seres humanos van construyendo caminos de sentido y de conciencia, también van incorporando en estas rutas reflexiones y decisiones sobre sus proyectos futuros. El proceso de creación de los microuniversos ha hecho que Dayana ${ }^{7}$ se cuestione sobre su papel en los trabajos desarrollados por ella con diferentes comunidades; su pequeño mundo nos remite a una vida de carencias, pero llena de sueños que escapan por una ventana, llevándola a la realidad que hoy habita, con menos carencias y más sueños. En este punto podríamos afirmar:

$6 \quad$ Norma Constanza Zamora (2014), Integrante de Ecología
en prácticas cotidianas.
$7 \quad$ Lady Dayana González (2014), Integrante de Ecología en
prácticas cotidianas.




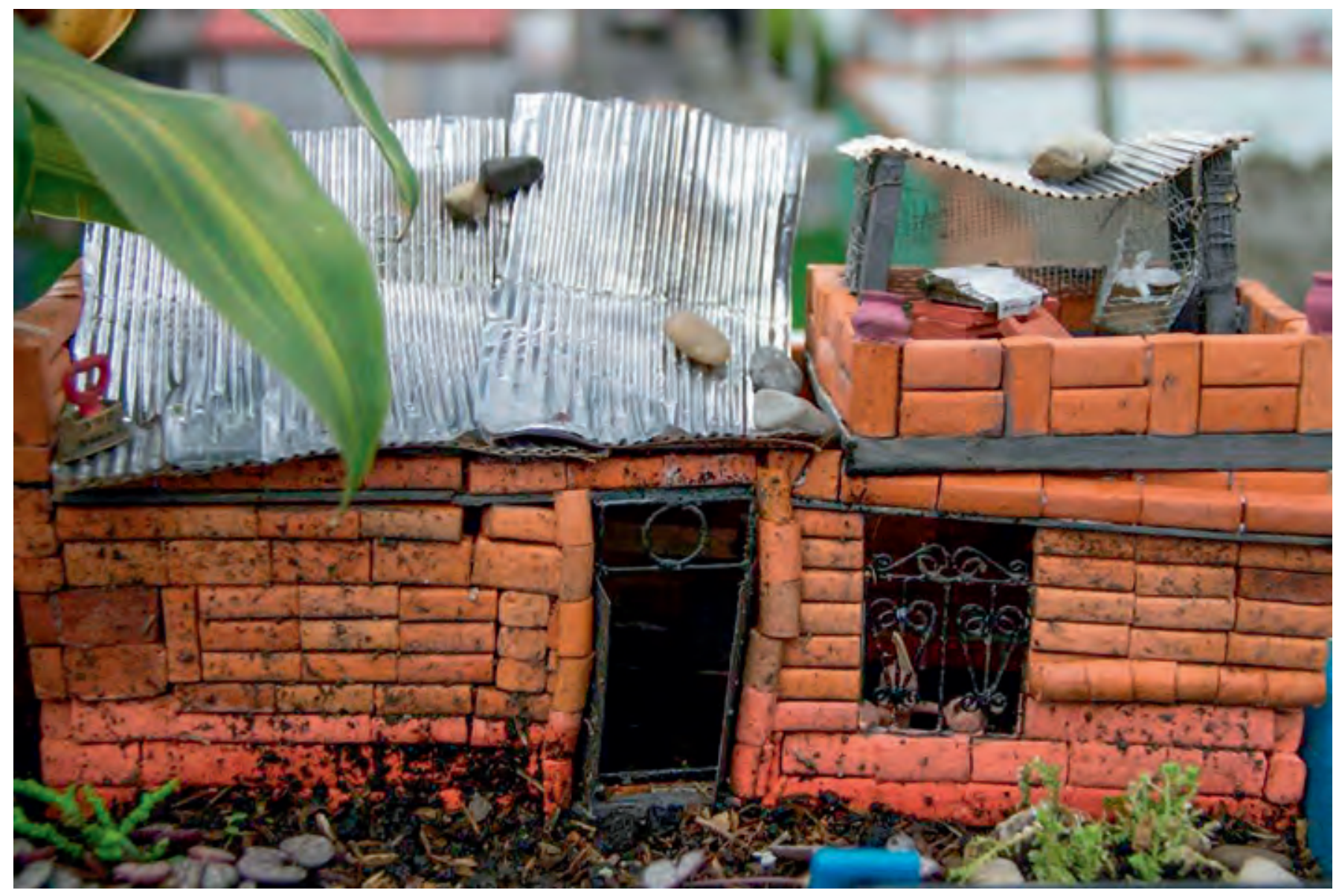

Imagen 9. El microuniverso de Lady Dayana González. Fotografía: Ligeya Daza Hernández (2014).

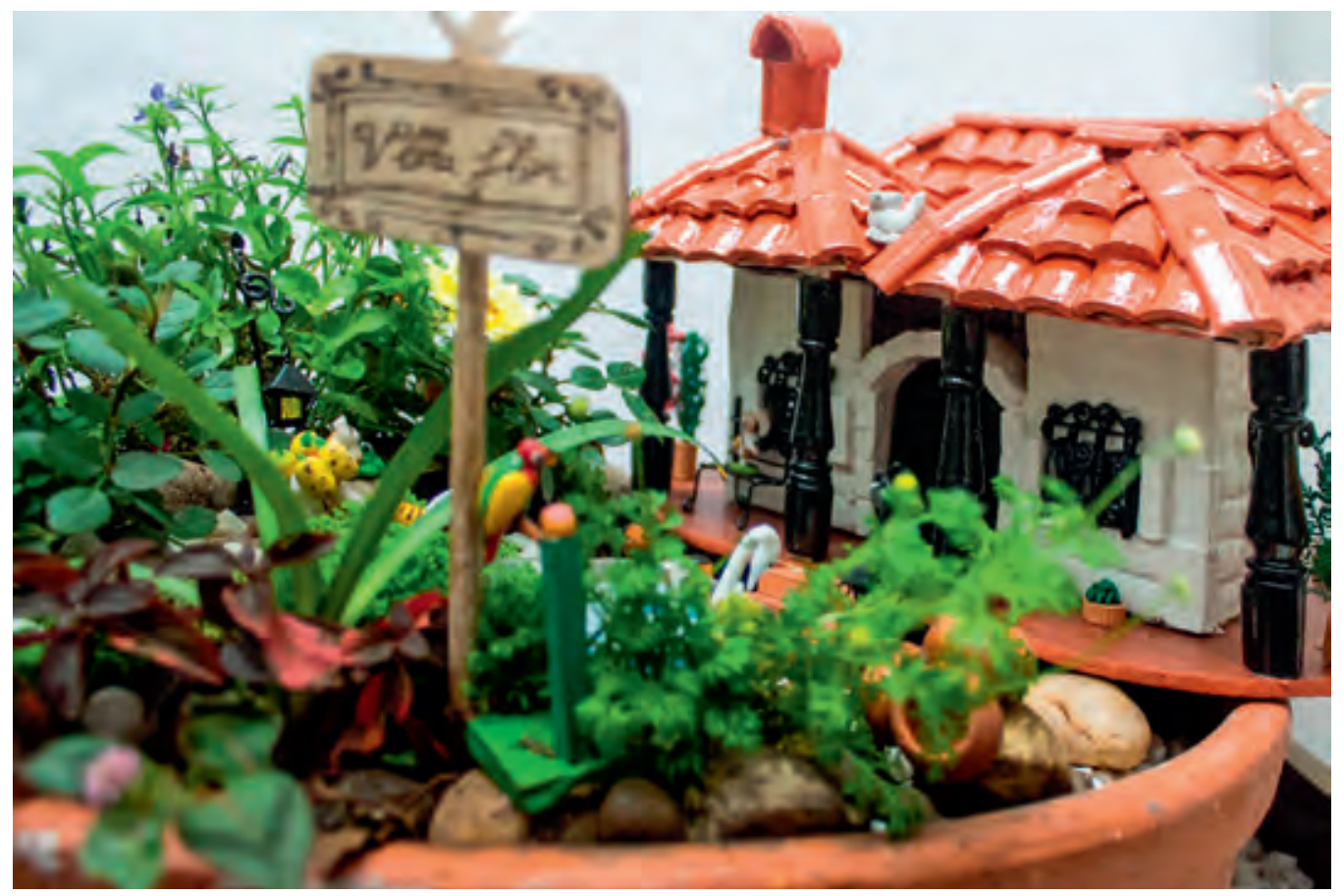

Imagen 10. El microuniverso de Flor María Vargas Coneme. Fotografía: Andrea Ortiz Díaz (2014). 
(...) Producir objetos físicos proporciona una visión interior de las técnicas de la experiencia capaz de modelar nuestro trato con otros. Tanto las dificultades como las posibilidades de hacer bien las cosas se aplican a la conformación de las relaciones humanas (Sennett, 2009, p. 355).

Leer la actividad de la construcción de microuniversos, que para muchas personas está instalada en lo cotidiano, nos lleva a entender que el resultado de ella se encuentra en su proceso interior, no en su proceso final; en este sentido, Nancy ${ }^{8}$ comenta:

\section{(...) A través de los ejercicios que íbamos reali-} zando los fines de semana, enfocados cada vez más en esa línea de la creatividad y mirando lo que hacían los compañeros, me inspiraba más y eso me emocionaba más.

Cualquier acción humana incorpora dentro de sí una potencia creadora que, proyectada en la acción, se dinamiza y recrea permanentemente. Cada ser humano posee una condición creadora con la que construye su vida, hace sus días, elabora cosas, teje relaciones sociales. Las acciones cotidianas requieren de un prolongado y exigente proceso de transformación; no son estáticas pues siempre existirá la posibilidad de que se realicen con menor esfuerzo y con mejor desempeño. Al respecto, Antony Giddens (2006) afirma que la “(...) acción es un proceso continuo, en un fluir en el que el registro reflexivo que el individuo mantiene es fundamental para el control del cuerpo que los actores de ordinario mantienen de cabo a rabo en su vida cotidiana" (p. 46). Este proceso de reelaboración permanente de la acción, que va evolucionando en su esfuerzo, agilidad y sincronía con otras acciones, está constituido por las sinfonías de los movimientos y haceres de nuestro devenir cotidiano; así nuestra melodía va siendo recreada en la acción, de la misma forma que la maestría de un músico va más allá de su destreza técnica en el uso de su instrumento. Vale la pena recordar que cuando el piano suena, vibra al unísono la naturaleza de su madera, la acústica del espacio sonoro, la historia de las cuerdas, las manos del técnico que las tensiona; en fin, otro microuniverso.

$8 \quad$ Nancy Stella Reyes (2014), participante en Ecología en prácticas cotidianas.

\section{Referencias}

Ardenne, P. (2006). Un arte contextual: Creación artística en medio urbano, en situación, de intervención, de participación. Murcia: Cendeac.

Bondenmann-Ritter, C. (2005). Joseph Beuys: Cada hombre, un artista. Madrid: Antonio Machado.

Bourriaud, N. (2006). Estética relacional. Buenos Aires: Adriana Hidalgo.

Capra, F. (1998). La trama de la vida: Una nueva perspectiva de los sistemas vivos. Barcelona: Anagrama.

Documenta und Museum Fridericianum VeranstaltungsGmbH. (2007). Documenta Kassel 16/06-23/09, 2007 [en línea]. Disponible en: http://archiv.documenta12.de/ geschichte010.html?\&L=1

De Certeau, M. (1996). La invención de lo cotidiano: 1 Artes de hacer. México: Universidad Iberoamericana.

Gablik, S. (1995). Connective Aesthetics: Art after individualism. En S. Lacy (Ed.), Mapping the terrain: New Genre Public Art (pp. 74-87) [en línea]. Disponible en: https://monoskop.org/images/7/7c/Lacy_Suzanne_ed_ Mapping_the_Terrain_New_Genre_Public_Art_1995.pdf

Garavito, E. (2013). De ignorancias e invenciones: Generación de conocimiento en acciones creadoras a través de una receta de cocina. Bogotá: Ministerio de Cultura.

Giannini, H. (2004). La "reflexión" cotidiana: Hacia una arqueología de la experiencia. Santiago de Chile: Editorial Universitaria.

Giddens, A. (2006). La constitución de la sociedad: Bases para la teoría de la estructuración. Buenos Aires: Amorrortou.

Joas, H. (1996). Creatividad, acción y valores: Hacia una teoría sociológica de la contingencia. México: Porrúa.

Joas, H. (2002). The Creativity of Action. Reino Unido: The University of Chicago Press.

Kester, G, H. (2004). Conversation pieces: Community + Communication in Modern Art. California: University of California Press. 
Laddaga, R. (1991). Estética de la emergencia. Buenos Aires: Adriana Hidalgo.

Lefebvre, H. (1991). Critique of Everyday Life: Volume I Introduction (J. Moore, Tr.), Londres: Verso. (Obra original: Critique de la vie quotidienne I: Introduction, 1947).

Martínez, A. M. y Simão, L. M. (2004). O Outro no Desenvolvimento Humano - Diálogos para a pesquisa e a prática profissional em psicologia. São Paulo: Pioneira Thomson Learning.

Mignolo, W. (2010). Geopolítica de la sensibilidad y del conocimiento: Sobre (de)colonialidad, pensamiento fronterizo y desobediencia epistémica [en línea]. Disponible en: http://eipcp.net/transversal/0112/ mignolo/es. [Consultado en diciembre de 2016].

Morin, E. (1996). El pensamiento ecologizado [en línea]. Disponible en: http://red.pucp.edu.pe/wp-content/ uploads/biblioteca/100115.pdf

Morin, E. y Hulot, N. (2008). El año I de la era ecológica. Barcelona: Paidós Ibérica.

Novo, M. (2007). Introducción. En M. Novo (Coord.), Mujer y medio ambiente: Caminos de la visibilidad. Utopías, educación y nuevo paradigma (pp. 11-14). Madrid: Los Libros de la Catarata.
Quijano, A. (1992). Colonialidad modernidad/ racionalidad. Perú Indígena, 13(29), pp. 11-20.

(2005). Colonialidade do poder, eurocentrismo e América Latina. A colonialidade do saber: Eurocentrismo e ciências sociais. Perspectivas latinoamericanas. Buenos Aires: Clacso [en línea].Disponible en: http://biblioteca.clacso.edu.ar/clacso/sursur/20100624103322/12_Quijano.pdf

Rancière, J. (2009). La división de lo sensible: Estética y política. (Fernández, A. trad.). (Obra original Le partage du sensible, 2000) [en línea] Disponible en: http:// poderesunidosstudio.files.wordpress.com/2009/12/ jacques-ranciere-la-division-de-lo-sensible1.pdf

Reguillo, R. (2000). La clandestina centralidad de la vida cotidiana. En A. Lindon (Coord). La vida cotidiana y su espacio-temporalidad (pp. 77-94). Barcelona: Anthropos.

Sennett, R. (2009). El artesano. Barcelona: Anagrama White, M. y Epston, D. (1993). Medios narrativos para fines terapéuticos. Barcelona: Paidós. 